\title{
Framing Stakeholder Involvement in Sustainable Port Planning
}

\author{
Matteo Ignaccoloa, Giuseppe Inturrib, Michela Le Pira ${ }^{a}$
}

This paper presents a framework to encompass stakeholder involvement in port planning processes, by specifically focusing on long-term strategic plans aimed at sustainability and designed to satisfy the needs of a port community and its surroundings. A classification of the main port stakeholders is presented together with some traditional and non-conventional tools and methods that can be used to support the participation process, according to the degree of participation and the steps of the plan. This analysis takes its clue from the results of the EU PORTA project, aimed at setting a new system of guidelines to integrate regional planning and port management. Port authorities and local policy-makers can use the output of this analysis to understand how to deal with the complexity of multi-actor decisions in port planning. By duly taking into consideration stakeholders' needs and concerns it will be easier to find the most shared solutions pursuing port sustainability.

\section{KEY WORDS}

$\sim$ Public participation

$\sim$ Port-City relationship

$\sim$ Participatory Planning

$\sim$ Stakeholder management

\begin{abstract}
a. Department of Civil Engineering and Architecture, University of Catania e-mail: matteo.ignaccolo@unict.it

b. Department of Electric, Electronic and Computer Engineering, University of Catania

e-mail: ginturri@dica.unict.it
\end{abstract}

\section{doi: 10.7225/toms.v07.n02.003}

This work is licensed under (cc) BY

\section{INTRODUCTION}

Sustainable development of ports relies on an appropriate planning and management of ports, balancing environmental, social, and economic interests through mediation and open dialogue (Wakeman, 1996). Globalization of production and consumption has induced structural changes in the interport/intra-port relations (Olivier and Slack, 2006). In order to guarantee the success of a port, port managers should succeed in managing the different stakeholders and interactions among them (Henesey et al., 2003). In this respect, if on one hand ports play a strategic role in the development of domestic and international trade, on the other they can have a strong impact on the livability of the local community hosting the port (Ignaccolo et al., 2013-A). For these reasons, port planning requires appropriate skills and procedures to be successful. Port planning has moved from a top-down approach (i.e. exclusively taking into account the 'strategic intent' of the port authority) to a bottom-up approach (i.e. taking into account the 'strategic intent' of different stakeholder categories, in addition to the strategic intent of the port authority) (Dooms et al., 2004). Therefore, it is important to involve all the stakeholders from the very beginning of the planning process, with different levels of involvement during the planning phases. Port community is very complex and articulated, with a lot of decision bodies and stakeholders with often conflicting objectives and interests. In this direction, port community systems have been emerging as electronic platforms for information exchange between public and private agents making available logistical information ${ }^{1}$. The participatory approach is quite recent in transport planning (Cascetta et al., 2015; Le Pira et al., 2018), while it is well established for land use planning (Arnstein, 1969). The European Union encourages the Member States to adopt Sustainable Urban Mobility Plans (SUMPs), fostering cooperation across different policy areas and sectors, across different levels of government and administration,

1. See, e.g., http://www.valenciaportpcs.com/en/. 
and in cooperation with citizens and other stakeholders. In port areas, the relationship between urban planning and port planning becomes fundamental to foster a joint sustainable development.

This paper presents a framework to encompass stakeholder involvement in the port planning processes by specifically focusing on port action plans (PAPs), i.e. long-term strategic plans focused on specific measures aimed at sustainability targets, based on the cyclical principle of Plan-Do-Check-Act. The remainder of the paper is organized as follows. Section 2 will present a succinct literature review on concepts and methodologies to involve stakeholders in sustainable port planning. Section 3 will present the methodology, by introducing the EU PORTA project, which inspired this research (3.1), the concept of PAPs (3.2), and a framework to include stakeholder involvement in PAPs (3.3). Section 4 will end the paper with the main conclusions and practical implications of the analysis performed.

\section{LITERATURE REVIEW}

The concept of "stakeholder" has been evolving from the first definition by Freeman (1984) ("any group or individual who can affect or is affected by the achievement of the organization's objectives"). Transport stakeholders are generically defined as "people and organizations who hold a stake in a particular issue, even though they have no formal role in the decision-making process" (Cascetta et al., 2015).

Identifying all the relevant stakeholders to involve in a decision-making process is not trivial. Decision context plays a fundamental role in understanding who the relevant actors are; therefore, a good knowledge of it is required (Le Pira, 2015). Some authors classify stakeholders on the basis of the type of interest they have in a plan/project: "primary stakeholders" are those who have a direct interest in the decision (e.g., transport operators or transport users), while "secondary stakeholders" are the ones who have an indirect interest (e.g. local communities) (Cascetta and Pagliara, 2013). They can also be categorized into three classes (Le Pira et al. 2016): experts (i.e. key informants), general stakeholders (e.g. institutions, groups, environmental associations, transport companies), and citizens (singles or in groups). While experts have high competence but low stake, stakeholders have competence and high stake, and citizens have low competence but act in the public interest.

For what concerns port planning and management, a first distinction should be made between internal stakeholders, who are part of the comprehensive port management, and external stakeholders, i.e. in situ and ex situ economic players (Notteboom and Winkelmans, 2002). They can be in turn categorized into: (1) institutions and authorities (public sector); (2) companies and operators (private sector); (3) local communities (or community stakeholders) (Ignaccolo et al., 2013-A). In Italy, an important role is played by the port management committee, a structure internal to the Port Authority, composed of members from local, regional, and maritime authorities, in charge of approving the port plans and the authorizations to operate inside the port ${ }^{2}$.

Several conflicts can arise among the different stakeholders. Port expansion is fundamental for port authorities to cope with market opportunities in the foreland-hinterland continuum, but can be hampered by external stakeholders (e.g. environmental pressure groups). In general, port policy should foster traditional micro-economic goals for port industries and operators, while central government usually pursues socio-economic objectives, aimed at an increase of the societal value-added of the national seaport system (Notteboom and Winkelmans, 2002).

Due to the variety of interests and objectives of each stakeholder, it is important to use appropriate methods and tools to support the participatory process. A review of typical tools and methods that can be used according to the characteristics of the process, e.g. degree of interaction, group size, time, and money needed, can be found in (Johnson and Dagg, 2003).

Besides, it is important to define the desired level of involvement, according to the well-known "ladder of citizen participation" (Arnstein, 1969). In transport planning, it is possible to identify five levels, according to the phases of the planning process (Cascetta and Pagliara, 2013), i.e.:

- Stakeholder identification, at the early stage of decisionmaking context assessment;

- $\quad$ Listening, during the analysis of the present situation and the identification of plan objectives;

- Information giving and consultation, while formulating and evaluating the alternative systems' projects;

- Participation, in the final choice.

Stakeholder mapping is a useful way to categorize stakeholders and understand their role/influence in the decision-making process (Aerts et al. 2015). In this respect, Social Network Analysis can be used to investigate social structures and to shorten the process of analyzing stakeholders (Le Pira et al., 2017-A). Stakeholders are the nodes of a network and are linked with the others according to their relationships (e.g. collaboration, information, competition). Stakeholder influence can be studied via indicators of centrality, according to their position and role in the network (Ignaccolo et al., 2013-A). The analysis could be further enhanced by studying how the flow of information and communication exchange among stakeholders could influence the outcome of a participation process oriented toward consensus building. In this respect, simulation models and, in particular, agent-based models (ABM), have been used in

2. Italian National Law $84 / 94$ titled "Riordino della legislazione in materia portuale" modified by D.Lgs. 169/2016. Available at: http://www.gazzettaufficiale.it/eli/ id/2016/08/31/16G00182/sg. 
the transport planning domain to explore the opinion dynamics in stakeholder networks, allowing the investigation of the role of network topology and other variables in reaching a shared decision (Ignaccolo et al., 2013-A; Le Pira et al. 2016; Le Pira et al., 2017-B). In the field of port planning and management, $A B M$ have been used, e.g. to reproduce port container terminal management, simulating stakeholders' relations for the analysis of operational policies for sustainable port and terminal management (Henesey et al., 2003).

Together with the methods that can be useful in a preliminary phase to carry out stakeholder analysis, appropriate decision-supporting methods and procedures have to be employed to develop effective participation processes (Le Pira et al., 2017-A). As an example, multi-criteria decisionmaking (MCDM) methods have been used in port planning and management to elicit stakeholder preferences, e.g. for alternative projects, according to multiple criteria of judgment (see, e.g. Dooms et al. (2004), Gonzalez-Urango and García-Melón, 2017).

All these methods can be used to support a participation process according to the desired degree of participation and the step of the planning process. However, recent findings show that, in general, actual stakeholder management practices convey moderate resemblance to the methods and theoretical findings presented in academic stakeholder management literature (Aerts et al. 2015).

Besides, it can be argued that some standardization of public involvement would be advantageous in port planning and management, e.g. with reference to environmental impact assessments of proposals for coastal development (Johnson and Dagg, 2003).

In what follows, a procedure to involve stakeholders in the long-term strategic planning of a port is presented, with the aims to bridge the gap between theory and practice of stakeholder involvement in port planning, and to support port management bodies in taking well thought out and shared decisions.

\section{METHODOLOGY}

\subsection{Background: the PORTA Project}

The EU PORTA 3 project (PORTs as a gateway for Access inner regions), supported by the European Regional Development Fund within the MED Program, aimed to define and implement common strategies and integrated transport/land use planning procedures for increasing the role of ports as strategic key actors of the maritime and logistics development and as gateways to access inner regions.

3. http://www.programmemed.eu/en/the-projects/project-database/results/view/ single.html?no_cache=1\&idProject=121.
The consortium, composed of academic, industrial, consultants and port authorities from Spain, France, Italy, Greece and Slovenia, proposed a new planning approach to overcome the dichotomy between maritime and transport policies and urban/local sustainable development of the areas surroundings the ports.

One of the outputs of the proposed port planning system consists of a "Guide on Port Action Plan" (PORTA, 2013). Its scope is to provide guidelines to port stakeholders and local authorities for the preparation and implementation of a "Port Action Plan" (PAP). The aim of a PAP is to integrate maritime policies in the port system with the process of land use/transport planning in the coastal regions.

In the following, the rationale behind the use of PAPs is presented.

\subsection{Port Action Plans (PAPs)}

A PAP is a strategic plan designed to satisfy the needs of a port community and their surroundings for a better quality of life. It has a long-term, planned horizon of 10 years, at least. It identifies problems and solutions to enhance the efficiency and sustainability of the port systems and relevant surrounding area (PORTA, 2013). It builds on existing planning practices and takes into proper consideration the integration with other planning sectors, public participation, and evaluation principles.

Typical objectives of a PAP are to:

- Decongest the maritime system bottleneck by coordinating transport modal shift policies;

- Limit pollution produced by the increased mobility of goods in coastal regions, especially when the emissions of trailer and semitrailer trucks are produced within the urban nodes to arrive to the harbor terminals;

- Promote intermodality solutions in urban seaports in order to boost the transfer traffic shares from unimodal road transport to Short Sea Shipping and combined transport;

- $\quad$ Enhance the accessibility of ports towards their hinterland and the home markets, so that maritime regions can economically benefit from the plan strategies.

The planning process is inspired by the principle of the Deming Cycle Plan-Do-Check-Act (PDCA) (Deming, 1950), an iterative four-step problem-solving model used to ensure continuous improvement of processes and optimal use of available resources, consisting of the following phases:

- $\quad$ Plan, i.e. setting up the objectives and actions necessary to deliver the expected results;

- Do, i.e. providing adequate resources and responsibilities to implement the actions;

- $\quad$ Check, i.e. adopting a monitoring system to measure the distance between the targets and performances; 
- Act, i.e. taking corrective actions to adjust the previous steps following the logic of continuous improvement.

The planning architecture is based on three hierarchic levels (Figure 1):

1. Strategic lines, which refer to global objectives that are relevant for the evaluation of the economic, social and environmental impacts of the plan;

2. Actions, which refer to specific objectives and evaluation of the results of the plan;

3. Operative measures, which refer to operational objectives and evaluation of the outputs of the plan.

A PAP is not a static picture of what the future of the port area is expected to be, but it is meant as a dynamic process subject to continuous monitoring and evaluation. According to this, it is important to identify global, specific and operational objectives that can be assessed respectively via: (1) impact indicators, to monitor the sustainability of the whole plan; (2) result indicators, to evaluate the performance of the actions of the plan; (3) output indicators, to monitor the implementation of the operative measures, which made up each action of the plan. Consequently, a PAP is not a list of operative measures without relations; on the contrary, it is composed of a series of actions, made up by several operative measures, and jointly converge towards strategic lines for economic, social, and environmental sustainable development of port systems (Ignaccolo et al., 2013B).

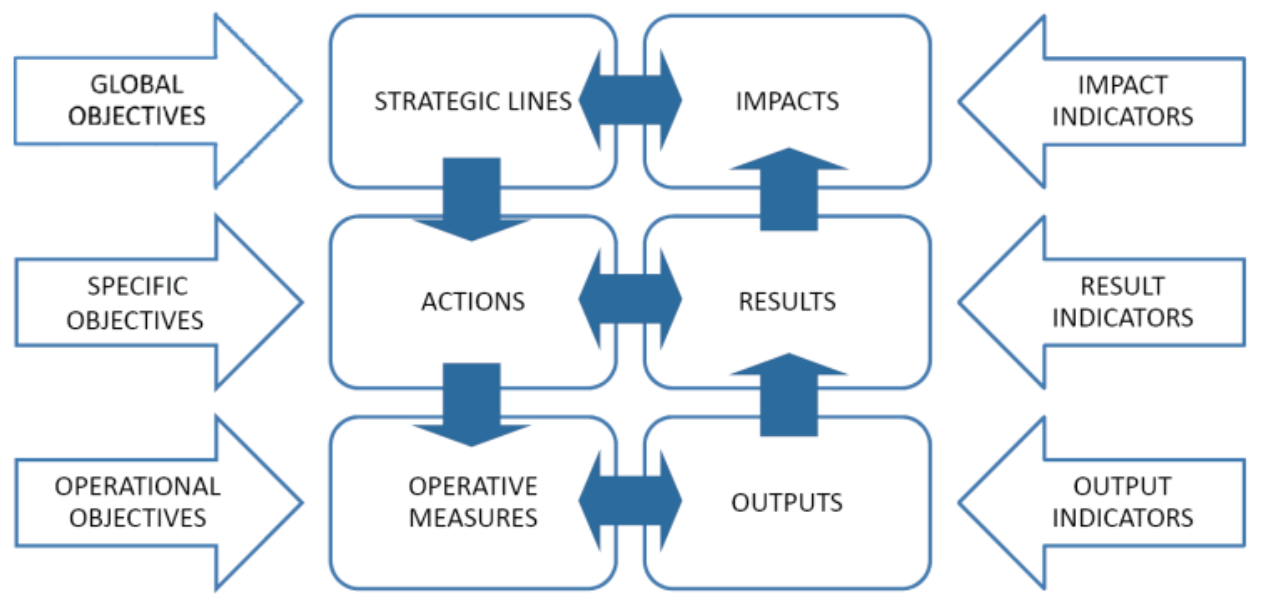

Figure 1.

PAP planning model (Source: Ignaccolo et al., 2013-B).

A PAP is composed of the following steps:

- P-Plan

- Territorial ambit of reference

- Stakeholder and Community Involvement

- $\quad$ Analysis of the state of the art

- $\quad$ SWOT analysis

- Scenario Analysis

- Analysis of the best practices and choice of the plan proposal

- $\quad P-D o$

- Implementation of the operative measures, actions and strategic lines

- C-Check

- Monitoring the plan

- A-Act

- Revision and re-assessment of the plan.
The University of Catania (Italy), as partner of the PORTA project, investigated the issue of public participation of the diverse stakeholders involved in the preparation of a PAP, and in particular the relationships between Port Authority and city/ citizens. Drawing from this experience, a framework to involve stakeholders in PAP processes is presented.

\subsection{Framing Stakeholder Involvement in PAPs}

According to the proposed planning model and the different levels of involvement described in section 2 , it is possible to frame stakeholder involvement in the steps of a PAP, as reported in Figure 2 and described below.

The first step of the planning process is to delimit the portion of territory where the impacts of the port system extend more directly their influence (territorial ambit of study), 
which is wider than the planning port area where the planning organization has the power to decide interventions (territorial ambit of intervention).

The territorial ambit of reference will give the input for the next phase of "Stakeholder and Community Involvement", mainly aimed at identifying the main stakeholders and plan the participation process. Involvement of citizens, public information and consultation with stakeholders should be taken into account from the very beginning of the formation of a PAP, in order to ensure maximum transparency and, consequently, social acceptability and improvement of the image of the port. The analysis of the state of the art is essential to provide a baseline against which any improvement can be measures. The main aims of this step are to: (1) gather all relevant data on the status quo of traffic, port activities and existing planning documents; (2) identify potential vulnerable elements (communities, health, environment, water quality, coastal areas, mobility issue, infrastructure, etc.); (3) prepare a baseline, together with key stakeholders, to identify and prioritize key problems to be addressed by the plan. In this phase, listening of stakeholder main concerns, together with information giving about the plan, are fundamental.

The SWOT analysis is a strategic planning tool used to evaluate the strengths, weakness, opportunities, and threats of a project (Ignaccolo et al., 2017). Both the "Analysis of the state of the art" and the "Scenario Analysis" described later on can benefit from this technique based on the building of a matrix with a critical reading of the port system. It consists of the identification of its strengths and weaknesses (endogenous factors), and the opportunities and threats that characterize its context (exogenous factors). Stakeholder consultation is of utmost importance to have a clear insight into the reality of the port system, the main critical issues to be solved, and the potential for its development. This will give the input to set up the objectives,

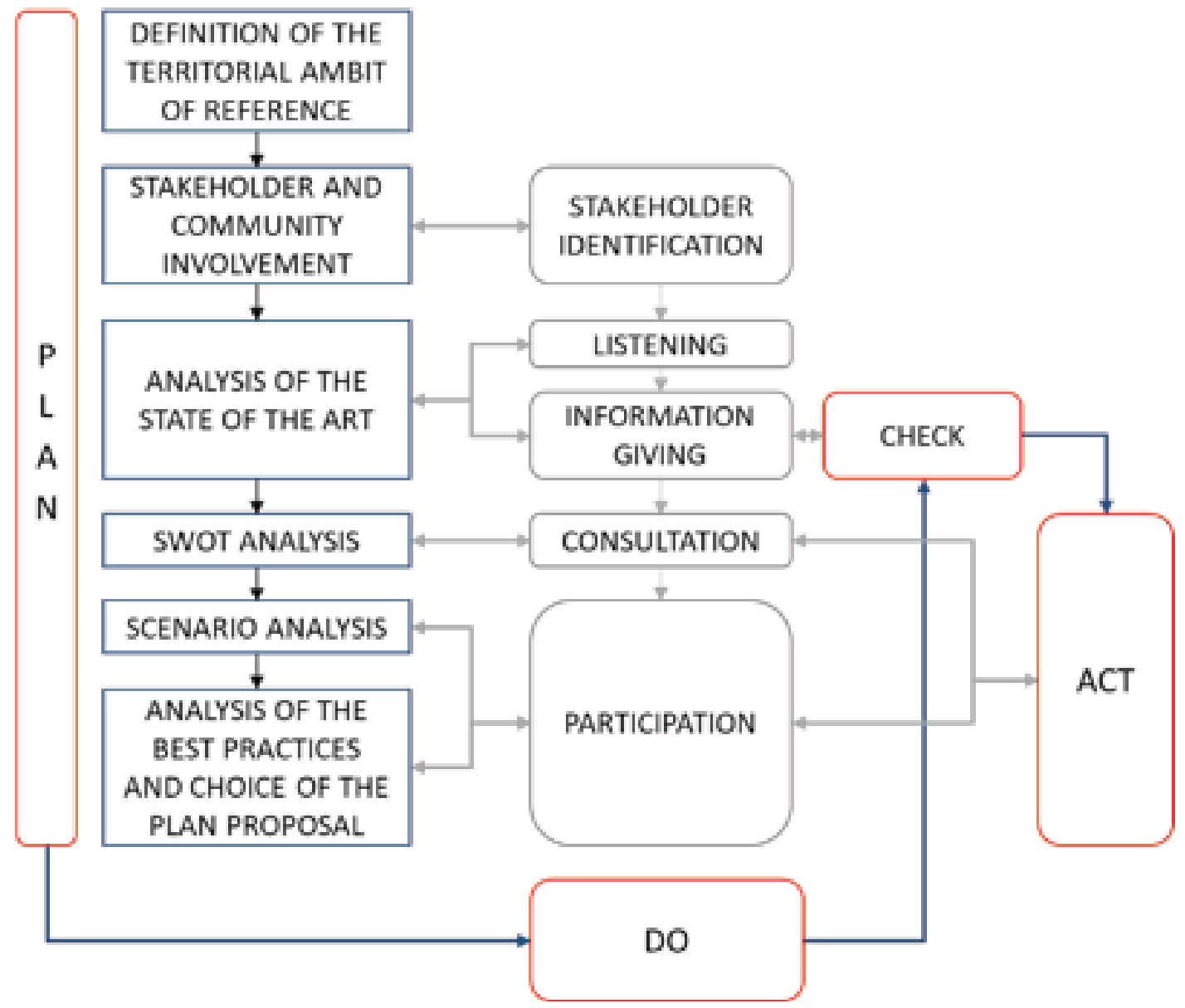

Figure 2.

Framework of stakeholder involvement in PAP process (Source: arranged from Ignacolo et al., 2013). 
indicators and actions necessary to deliver the expected results as described in Figure 1.

After developing the "do-nothing" scenario by predicting exogenous trends in the absence of any action, and the "businessas-usual" scenario which provides the implementation of the actions already programmed, a set of "alternative scenarios" resulting from different alternative policies and choices has to be analyzed. Scenario analysis is performed by comparing the effects of the different scenarios via a set of indicators. This is done by involving all relevant stakeholders to discuss the impact of alternative planning policies and make them participate in the evaluation process. To this aim, it is important to keep the results understandable for non-technicians. Appropriate techniques, mainly based on quantitative models, such as those described in section 2, have to be put in place to choose which strategy serves the community vision in the most effective way.

In the last step of the "Plan" phase, a package of effective actions is selected by actively asking the participation of stakeholders also in the choice of result indicators and targets that allow monitoring of progress towards the specific and general objectives already shared. This step can benefit from the lessons learnt from the best practices, widely available from databases of European projects, taking into account their pertinence with the sustainability objectives to be realized and their degree of transferability within different contexts.

Stakeholder involvement should be assured also in the "Check" and "Act" phases of the Deming cycle, i.e. by respectively (a) keeping them informed on the monitoring system and process set up to measure the distance between targets and performances, and (b) involving them so to take corrective actions to adjust the previous steps following the logic of continuous improvement.

Table 1 resumes the PAP steps with the related levels of stakeholder involvement and methods and tools suggested for each step, based on the literature review performed in section 2 .

In this respect, stakeholder mapping and social network analysis can be used in the first phase of "stakeholder identification", to have a clear insight on the actors to involve and their role in the decision-making process.

Informative workshops and individual interviews are well suited for listening and information giving purposes, while focus groups on specific topics, involving small stakeholder groups (Le Pira et al., 2017-A), are more appropriate to consult them and have a clear insight into the reality of the port system.

Scenario analysis with stakeholders could benefit from the use of quantitative methods, such as (group) multi-criteria decision-making (MCDM) methods, to elicit their preferences toward specific objectives and strategies.

Consensus conferences are necessary to reach a convergence of opinions toward a shared plan (Le Pira, 2015). In this respect, starting from the results of stakeholder mapping and social network analysis, agent-based models can be used to analyze the conditions that would likely lead to consensus building in a network of stakeholders, thus helping to carry out effective consensus meetings.

Public meetings can be organized to inform stakeholders about the monitoring process, while focus groups and workshops, also in this case supported by the use of MCDM methods, are more suitable to revise and reassess the plan.

Table 1.

Framing stakeholder involvement in PAPs.

\begin{tabular}{llll} 
PDCA phase & PAP Phase & Level of involvement & Suggested methods \\
\hline $\mathrm{P}$ & Territorial ambit of reference & - & - \\
\hline $\mathrm{P}$ & $\begin{array}{l}\text { Stakeholder and Community } \\
\text { Involvement }\end{array}$ & Stakeholder identification & $\begin{array}{l}\text { Stakeholder mapping, social network } \\
\text { analysis }\end{array}$ \\
\hline $\mathrm{P}$ & Analysis of the state of the art & Listening, Information giving & Workshops, interviews \\
\hline $\mathrm{P}$ & SWOT analysis & Consultation & Focus groups \\
\hline $\mathrm{P}$ & Scenario Analysis & Participation & Workshops + MCDM methods \\
\hline $\mathrm{P}$ & $\begin{array}{l}\text { Analysis of the best practices and } \\
\text { choice of the plan proposal }\end{array}$ & Participation & Consensus conferences + ABM \\
\hline D & $\begin{array}{l}\text { Implementation of the operative } \\
\text { measures, actions and strategic lines }\end{array}$ & - & - \\
\hline C & Monitoring of the Plan & Information giving & Public meetings \\
\hline A & $\begin{array}{l}\text { Revision and re-assessment of the } \\
\text { plan }\end{array}$ & Consultation, Participation & Focus groups, workshops + MCDM \\
& & & methods
\end{tabular}




\section{DISCUSSION AND CONCLUSION}

Stakeholder involvement and management is becoming fundamental to guarantee an appropriate and sustainable development of ports. This paper presented a framework to encompass stakeholder involvement in port planning, by proposing different levels of involvement in the decision-making process, and suggesting methods to support it. The focus of the analysis is on port action plans, i.e. long-term strategic plans aimed at sustainability and based on the logic of the Plan-DoCheck-Act cycle.

Some of the methods proposed are techniques or practical tools to help conducting effective participation processes (i.e. workshops, interviews, focus groups, consensus meeting, public meeting, workshops with the use of MCDM methods), while others rely on desk analysis aimed at guiding and supporting the management of participation processes (i.e. stakeholder mapping, social network analysis, agent-based models).

It is worthy of notice that the framework proposed is comprehensive and should be adapted to the specific context under study. In this respect, stakeholder involvement is not an easy task and requires resources and ad-hoc skills to be developed. Therefore, it is important to plan the participation process well in advance by duly taking into account the resources available to carry it out.

Nevertheless, the proposed framework can be used by port authorities and local policy-makers as a guide to plan the sustainable development of ports and to understand how to deal with the complexity of multi-actor decisions in port planning.

\section{REFERENCES}

Aerts, G., Dooms, M. and Haezendonck, E., 2015. Stakeholder management practices found in landlord seaport authorities in Flanders: an inside-out perspective. International Journal of Shipping and Transport Logistics, 7(5), pp. 597-620. Available at:

http://dx.doi.org/10.1504/ijstl.2015.072019.

Arnstein, S.R., 1969. A ladder of citizen participation. Journal of the American Institute of planners, 35(4), pp. 216-224.

Cascetta, E. and Pagliara, F., 2013. Public Engagement for Planning and Designing Transportation Systems. Procedia - Social and Behavioral Sciences, 87, pp. 103-116. Available at:

http://dx.doi.org/10.1016/j.sbspro.2013.10.597

Cascetta, E. et al., 2015. A new look at planning and designing transportation systems: A decision-making model based on cognitive rationality, stakeholder engagement and quantitative methods. Transport policy, 38, pp. 27-39.

Deming, W.E., 1950. Elementary Principles of the Statistical Control of Quality. JUSE.

Dooms, M., Macharis, C. and Verbeke, A., 2004. Proactive stakeholder management in the port planning process: empirical evidence from the Port of Brussels. 44th Congress of the European Regional Science Association: "Regions and Fiscal Federalism", Porto, Portugal, August 25 - 29.

Freeman, R.E., 1984. Strategic management: A stakeholder approach. Boston: Pitman.
Gonzalez-Urango, H., \& García-Melón, M. 2017. A Multicriteria Model to Evaluate Strategic Plans for the Nautical and Naval Industry in Cartagena de Indias, Colombia. Sustainability, 9(4), pp. 653. Available at:

http://dx.doi.org/10.3390/su9040653.

Henesey, L., Notteboom, T. and Davidsson, P., 2003. Agent-based simulation of stakeholders relations: An approach to sustainable port and terminal management. Multi-Agent Systems for Container Terminal Management, 99.

Ignaccolo, M. et al., 2013-A. The role of Public Participation in sustainable port planning. PORTUS 26, ISSN: 2282-5789.

Ignaccolo, M. et al., 2013-B. A planning process framework for a port action plan: the city - port relationship. Proceedings of the 13th World Conference on Transport Research (WCTR), Rio de Janeiro, Brasil, July 15-18.

Ignaccolo, M. et al., 2017. Structuring transport decision-making problems through stakeholder engagement: Transport Infrastructure and Systems: Proceedings of the AlIT International Congress on Transport Infrastructure and Systems, Rome, Italy, April 10-12, pp. 919-926. Available at: http://dx.doi.org/10.1201/9781315281896-119.

Johnson, D.E. and Dagg, S., 2003. Achieving public participation in coastal zone environmental impact assessment. Journal of Coastal Conservation, 9(1), pp. 13-18. Available at:

http://dx.doi.org/10.1007/bf02755521.

Le Pira, M. et al., 2016. Modelling stakeholder participation in transport planning. Case Studies on Transport Policy, 4(3), pp. 230-238. Available at: http://dx.doi.org/10.1016/j.cstp.2016.06.002.

Le Pira, M. et al., 2017-A. Towards a decision-support procedure to foster stakeholder involvement and acceptability of urban freight transport policies. European Transport Research Review, 9(4). Available at:

http://dx.doi.org/10.1007/s12544-017-0268-2.

Le Pira, M. et al., 2017-B. Finding shared decisions in stakeholder networks: An agent-based approach. Physica A: Statistical Mechanics and its Applications, 466, pp. 277-287. Available at:

http://dx.doi.org/10.1016/j.physa.2016.09.015.

Le Pira, M. et al., 2018. Dealing with the Complexity of Stakeholder Interaction in Participatory Transport Planning. Advanced Concepts, Methodologies and Technologies for Transportation and Logistics, pp. 54-72. Available at: http://dx.doi.org/10.1007/978-3-319-57105-8_3.

Le Pira, M., 2015. Towards participatory decision-making processes in transport planning: an agent-based approach. Doctoral dissertation, University of Catania, Italy.

Notteboom, T., and Winkelmans, W., 2002. Stakeholders relations management in ports: dealing with the interplay of forces among stakeholders in a changing competitive environment. Conference proceedings of IAME 2002, International Association of Maritime Economists Annual Conference 2002, Panama City.

Olivier, D. and Slack, B., 2006. Rethinking the Port. Environment and Planning A, 38(8), pp. 1409-1427. Available at: http://dx.doi.org/10.1068/a37421.

PORTA (2013). Guide on Port Action Plan. Deliverable of the EU PORTA Project. Available at: http://www.programmemed.eu/en/library/deliverables-detail. html?tx_ausybibliomed_pi1\%5Blivrable\%5D=448\#.WnGqDKjiY2w

Wakeman, R., 1996. What is a sustainable port? The relationship between ports and their regions. Journal of Urban Technology, 3(2), pp. 65-79. 